\title{
Consequences of teleworking using the internet among married working women: Educational careers investigation
}

\author{
Nooshin Pordelan $^{1}$ (D) Simin Hosseinian ${ }^{2}$ (D) Hamid Heydari ${ }^{3}$ (D) \\ Sadaf Khalijian ${ }^{4}$ (D) Mohammad Khorrami $^{5}$ (D)
}

Received: 15 March 2021 / Accepted: 13 October 2021 / Published online: 23 October 2021

(c) The Author(s), under exclusive licence to Springer Science+Business Media, LLC, part of Springer Nature 2021

\begin{abstract}
Nowadays, women constitute a considerable part of employees in the society that according to the multiple roles that they play (mother, wife, employee), more flexibility is needed in their career affairs. This study aimed to investigate the effects of teleworking using the Internet on married working women working in educational settings (advantages and disadvantages of teleworking). For this purpose, this study includes qualitative and quantitative parts with samples including 16 and 404 married women working in educational settings (i.e. school and university). In the qualitative part that interviews were conducted with 16 married women who were selected as experts in educational occupations, the findings showed that teleworking brings six major advantages for women. These six advantages are economic, psychological, health, family, organizational, and educational. Moreover, when the qualitative part was ended, the researchers prepared a questionnaire according to the findings and selected 404 married and working women in educational settings to rate advantages and disadvantages of teleworking during Covid-19 pandemic and according to qualitative results, teleworking has disadvantages such as role conflict, lack of face-to-face position, and reworking. The quantitative results showed that participants' feedback was positive in six advantages and two variables of family and psychological were the most important variables among teleworking advantages $(\mathrm{p}<.05)$. According to the findings of this study, it can be concluded that teleworking has a considerable effect on family cohesion and psychological security of women. Therefore, according to the current status of the society (covid-19), facilities should be considered for married women.
\end{abstract}

Keywords Teleworking · Working women · Internet-based teleworking · Educational careers $\cdot$ Covid-19 pandemic

Hamid Heydari

mr.heydari1957@gmail.com

Extended author information available on the last page of the article 


\section{Introduction}

Teleworking is a special type of career in which the employee works out of his workplace. The characteristics of this activity include reduced need for transportation and working based on fixed schedules (Sládek \& Sigmund, 2021). Jack M. Nilles (1998) was the first person who officially started investigations on teleworking and he is known as "teleworking godfather" in different books. He was a leader of a multidisciplinary team in 1973. The purpose of this team was to study issues related to the policies of the federal government in the field of "creating compatibility between telecommunications and transportation" and it was not expressed easily. As a result of clear modifications, "telecommuting" was selected. However, since this term had limited use, it was replaced by "teleworking" that represented vast uses (Kurland \& Bailey, 1999). Also, authors such as Toffler (1980) presented Electronic Cottage and in 1983, Williams used the term electronic renaissance. Kinsman (1987) published the first book entitled "Teleworkers" in which he predicted teleworking and flexible labor revolution.

In the 1980s, Olson and Primps (1984) suggested that over 50\% of workers can be teleworkers. One of the main advantages of teleworking is that it allows people reconcile work and family. Since 1990s, many authors agreed that this reconciliation is a serious challenge that societies suffer from and that teleworking is an ideal choice for this challenge (Gregory \& Milner, 2009).

In this study, the researchers used the research method and statistical sample selection to reach theoretical saturation and interviews women expert in educational settings and investigated details in the quantitative part. The details are presented in the research method section.

\subsection{Teleworking during Covid-19 pandemic}

The global outbreak of Covid-19 has caused social distancing to prevent this virus. Many careers have reduced the amount of physical presence in the workplace due to quarantine and forced holidays or have stopped their activities. Some workers are easily transferred to the teleworking system. In many careers, teleworking is impossible and has made many workers to look for another career. It is important to investigate both groups of workers to evaluate costs and advantages of virus prevention policies and developing optimal reopening strategies (Jones et al., 2020; Baqaee et al., 2020; Leibovici et al., 2020) and teleworking (Adams-Prassl et al., 2020; Bick et al., 2020).

During Covid-19 pandemic, teleworking became popular for the first time in developing countries (Nguyen, 2021). Although Covid-19 pandemic created many problems for all social indexes such as health, it led to the flourishing of some capabilities in Iran such as spread and flourishing of virtual education and teleworking throughout the country (Ghafourifard, 2020). However, employees in Iran face a variety of problems for teleworking such as lack of teleworking skills among managers, lack of career skills and suitable knowledge in the context of teleworking, lack of ability to do works as a team, lack of awareness and access to all data, reduced job 
security risk, lack of access to all courses, and the risk of feeling ignored (Fathian \& Jahani, 2020). With all the problems that exist in teleworking in Iran, in recent years and with the spread of Covid-19, the government welcomed teleworking, because this method does not need physical presence and leads to reduced infection.

Teleworking is a concept that is highly connected to information technology and communications development and is introduced with titles such as telecommuting, flexiplace, remote work, and working from home. Mostly, this concept is defined as working inside the house (Groen et al., 2018) while the common element of teleworking is not house and it is the use of computer and remote communication technology where form and domain of work is changed (Pulido \& Lopez, 2005). Teleworking points to activities that include telecommunication from places other than the workplace. In other words, teleworking is a method to organize and do a job using information technology and allows employees perform their duties outside the workplace (Sládek \& Sigmund, 2021).

According to Kurland and Bailey (1999), one of the advantages of teleworking at the individual level is its positive effect on the balance between work and life. Teleworking plan is a social support to help workers, so that they can work and benefit from financial independence and perform their parental roles (Moore, 2006). The advocates of this plan believe that it is an excellence choice for work and taking care of children in the house at the same time (Shojanoori et al. 2015). Teleworking creates working flexibility and leads to a balance between work and family (Darouei \& Pluut, 2021). Increasing the level of temporal and spatial flexibility is one of the advantages of teleworking to promote work and life balance. Teleworking presents a complete spectrum of new opportunities about work-life balance as follows:

- More control over work plans and speed

- Reduce traffic time that create more opportunities to spend time with family

- Balance work to take care of children or elderlies who need more care

- Create an opportunity for parents with newborn babies for part-time jobs and stop working sooner (Moore, 2006).

\subsection{Teleworking for married women}

Ensuring psychological health for married working women is one of the important factors in the stability and sustainability of family and society (Khorrami et al., 2019). With more and more married women working outside the family boundaries, they experience multiple roles and duties with expectations to do different things to ensure family cohesion. In sum, they play different roles. With women entering the labor market, their previous role changes considerably and a new role will be added to mother and wife roles and occupational role (McIntosh, 2005). Combination of occupational and family roles puts pressure on working women (Tan and Lim 2021) that necessitates balance between working outside and inside the house and teleworking (Boca et al., 2020).

Various studies have shown that people who do their work at home show higher efficiency compared to people who work at the office (Lister \& Harnish, 2019). The 
results of a study by Fílardí et al. (2020) showed that teleworking has advantages such as better life quality, family and work balance, greater productivity and flexibility, possibility to create standard criteria, better work assessment, reduced costs, stress, and transportation.

It has been observed that deciding on the participation of people in teleworking is one of the important variables that is dependent on their career or gender (Gold \& Mustafa, 2013; Jaakson \& Kallaste, 2010). In the meantime, working women, due to their experience about work/non-work role conflict and more career interruptions compared to men (Balali et al., 2017) and high flexibility in teleworking (Chung \& Van der Horst, 2018) make this method more attractive.

The role of women as family supporters has a considerable effect on their teleworking experiences. The sense of responsibility of women towards family members, raising children, and social and family roles have influenced their values, behavior, and attitudes. Due to temporary autonomy and that they can reduce time pressure with planning, working women consider teleworking a positive opportunity to promote their life quality. However, life quality may not be desirable but teleworking is a personal choice (Hilbrecht et al., 2008).

Boca et al. (2020) in a study in Italy showed that working women who have 0 to 5 years old children face a challenging balance between work and family during Covid-19 pandemic. Achievement to this balance is more difficult for people who have a partner and work outside the house under emergency conditions. The results of a qualitative study by Gálvez et al. (2020) in Spain showed that women resorting to teleworking criticize the existing employment models in the market. Mokhtarian and Salomon (1994) stated that women take advantage of teleworking more than men and women choose part time work. In 2005, about $18 \%$ of European workers preferred part time work. In Belgium, $40 \%$ of women have part time works while this number for men is $7 \%$. These numbers show that part time work is more important for women, because part time workers have better work-family balance. Gender stereotypes and social norms define work as the basis and foundation of masculine identity and raising children as a feminine role. Until the income gap between men and women continues and women's careers are considered low-paying and lowreward careers, for some women, the role of motherhood is an important self-fulfillment, satisfaction, and autonomy source. Lack of different accepted roles for men in the society is the reason that men prefer full time work and consider themselves as the main financial source of the family (Vandeweyer \& Glorieux, 2008). For Iran where more than half of those admitted to the entrance exam are women and its culture pays a special attention to the role of women in the house and training children, teleworking can be beneficial.

\subsection{The role of technology in teleworking}

Security is one of the standards that is of crucial importance in teleworking (Souppaya \& Scarfone, 2016). However, in Iran, information technology infrastructures are not safe (Nozari et al., 2020). Some of these infrastructures include lack of information security, lack of familiarity with communicative and educational problems 
of managers and staff, low internet access, high telecommunication costs, undesirable communicative services distribution in rural and local areas, high costs of hardware equipment, lack of access to the required knowledge in performing the duties, and expensive software systems (Fathian \& Jahani, 2020). Therefore, it can be said that in Iran, teleworking infrastructures are not provided desirably because technology has an important role in the development of teleworking and for this reason, technological infrastructures are needed. On the other hand, Belzunegui-Eraso and Erro-Garcés (2020) considered ICT a major factor for teleworking. They analyzed technology appropriateness for specific work role. In this context, intensity of information technology is considered in teleworking processes. Increased use of technology and its advancements and communications have led to the development of teleworking (Messenger \& Gschwind, 2016; Belzunegui-Eraso \& Erro-Garcés, 2020). Moreover, extensive and constant use of different technologies, especially computers and microelectronics, facilitates teleworking development. The use of virtual system, telematics, and computer procedures provide the context for remote activities within an organization. Previous studies on the effect of ICT-mobile work on teleworking showed that there is a positive relationship between technologies and possibility to work outside the employer buildings) Vargas-Llave et al., 2020). Communication and information technology-based methods create flexible working contexts such as flextime that increase the autonomy of employees (Chung \& Van der Horst, 2018).

\section{The purpose of the study}

The purpose of this study was to estimate potential and real consequences of teleworking and use of technology among working women. The fact is that global hazards due to new diseases such as Covid-19 can be considered as teleworking motivators. This hazardous condition intensifies and becomes a more comprehensive issue for the future and it should be taken into consideration based on experiences and conditions of different cultures. Moreover, on the one hand, teleworking provides the possibility for constant organizational activities and on the other hand, teleworking ensures collective health of employees. Beck and Wynne (1992) have warned about the global consequences of different phenomena and the potential effects on the world. These aspects demand new thinking processes about global threats. However, to reduce these dangers at the global level, their management should be taken into consideration from local or regional perspectives. Accordingly, companies have imagined that teleworking can facilitate management of health crisis effect on production activities, especially during Covid-19 pandemic.

However, in Iran, the issue of teleworking for married and working women has specific features and finding answers through studies conducted outside the Iranian context is difficult. These unique features need local studies in this context. Iran is a particular country in the region that increasingly promotes its research system (Kharabaf \& Abdollahi, 2012) and studies in Iran on teleworking are developing. But most of these measures are performed quantitatively or are based on trial and error and married working women are rarely taken into consideration. In addition to 
quantitative studies, qualitative approaches provide researchers with vital and valuable information (Woods, 2006).

The results of this study are important since it is conducted on teleworking during Covid-19 pandemic and in previous studies before 2019, teleworkers were not forced to quarantine themselves in the house and could easily use their time outside the house. Therefore, this study can expand previous studies. According to what has been said and that this study has been conducted in qualitative and quantitative parts, the purpose of this study is to answer the following questions:

1. What are the advantages and disadvantages of teleworking for married women working in educational settings during Covid-19 pandemic?

2. How the advantages and disadvantages of teleworking are rated for married women working in educational settings during Covid-19 pandemic?

\section{Method}

\subsection{Participants}

This study includes qualitative and quantitative parts. In the qualitative part, researchers investigated the effects of teleworking on working women during Covid19 pandemic using qualitative research method and then, they created a questionnaire according to interviews from the quantitative part to investigate the opinions of other people working in educational settings in a wider sample. Therefore, in the second part of the study and after distributing the questionnaires, construct validity was examined using confirmatory factor analysis and then, the results obtained from the final model were analyzed. In the following, both methods will be explained separately. In the current study, all participants are females. Females were selected as the research sample because in Iran, women are faced with more occupational problems than men and enter the labor market with a delay compared to women in developed countries (Rafatjah \& Kheirkhah, 2012).

The demographic information of the participants is presented in Table 1.

Table 1 shows that 16 people have participated in the qualitative part and 404 people have participated in the quantitative part.

Since theoretical saturation was a basis for sample selection (Hesse-Biber\& Leavy 2010), for sample selection in the qualitative part, purposive sampling was

Table 1 Demographic characteristics of the participants

\begin{tabular}{|c|c|c|c|c|c|}
\hline & \multirow[t]{2}{*}{ Number } & \multicolumn{2}{|l|}{ Age } & \multicolumn{2}{|c|}{ Working background } \\
\hline & & Minimum & Maximum & Minimum & Maximum \\
\hline Qualitative & 16 & 32 & 59 & 10 & 30 \\
\hline Quantitative & 404 & 29 & 61 & 10 & 32 \\
\hline
\end{tabular}


used and the selection process continued until theoretical saturation and finally, the number of participants reached 16.

\subsection{Procedure}

This study has two parts of research method.

\subsubsection{The qualitative part}

In the qualitative part and in terms of purpose, this study is a developmental-applied study where Grounded theory approach is used. For data collection, interview was used. For sampling, purposeful sampling (snowball method) was used. A sample including university lecturers and teachers who can provide the most useful information was selected. Meanwhile, according to the sampling method, the respondents were asked to introduce other informed people. Therefore, these criteria were considered for interview:

- The interviewee is somehow related to education.

- The interviewee is a married woman.

- The interviewee is involved in teaching as a teleworker.

- The interviewee is familiar with teaching and teleworking.

The statistical population in the qualitative part includes scholars, professors, and teachers. In this study, 16 people are selected as interviewees and after 14 interviews, the researcher concluded that the data collection has reached a theoretical saturation point but for complete assurance, the process continued until the end of the $16^{\text {th }}$ interview. The characteristics of the participants are presented in Table 2.

According to the Grounded theory by Strauss and Corbin (1997), appropriate sample includes 10 to 25 people and its increase is dependent on theoretical saturation. In this study, 16 interviews were conducted and after the $14^{\text {th }}$ interview, no new data was obtained and theoretical saturation was achieved. However, for more assurance, interviews continued until the $16^{\text {th }}$ interview. These people were selected based on snowfall method.

Interviews lasted for about $28 \mathrm{~min}$ and recoded by digital devices. Interviews were listened as soon as possible and were written word by word. For data analysis, content analysis method was used. These stages included the following steps. First of all, the entire interview was written. The entire interview text was read to get a general understanding. Basic units and codes were identified. Similar codes were classified and placed in more general classes and hidden content in data was determined. Some parts of interview texts with their codes and obtained classes were sent to a supervisor to validate the analysis. Also, some parts of interview texts and codes and classes were sent to a professor and a colleague to investigate analyses and state their corrective opinions.

To observe ethical considerations, in the beginning of interviews, the participants were provided with information about the purpose of the study, interview procedure, 
Table 2 General characteristics of the participants in the interview

\begin{tabular}{lllll}
\hline Row & Field of study & Level & Career & $\begin{array}{l}\text { Back- } \\
\text { ground } \\
\text { (year) }\end{array}$ \\
\hline 1 & & & & 30 \\
2 & Consultation and guidance & Ph.D & University lecturer & 12 \\
3 & Psychology & Ph.D & University lecturer & 13 \\
4 & career counseling & M.A & teacher & 20 \\
5 & Elementary education & B.A & University lecturer & 22 \\
6 & Theology & B.A & teacher & 10 \\
7 & Educational technology & M.A & teacher & 21 \\
8 & Computer engineering & Ph.D & University lecturer & 18 \\
9 & Educational technology & Ph.D & University lecturer & 15 \\
10 & Educational technology & M.A & teacher & 20 \\
11 & Biology & Ph.D & University lecturer & 23 \\
12 & Educational technology & M.A & teacher & 19 \\
13 & Math & M.A & teacher & 17 \\
14 & Geography & Ph.D & University lecturer & 16 \\
15 & Psychology & M.A & teacher & 21 \\
16 & Literature & B.A & teacher & 23 \\
\hline
\end{tabular}

privacy, and their rights regarding participation or lack of participation. Informed consents were received from the participants. Time and place of interviews were determined with the coordination and agreement of the participants so that there is no disturbance in their daily life. The principle of confidentiality of all information was strictly observed at all stages. In the following, the interview questions are presented.

1. Can teleworking using the Internet during Covid-19 be useful for working women? 2. Can teleworking using the Internet during Covid-19 be useful for organizations in which working women work? 3. Can teleworking using the Internet during Covid-19 be useful for a society or country in which working women work? 4. Can teleworking using the Internet during Covid-19 be useful for families in which working women work? 5. What are further advantages and disadvantages of teleworking using the Internet during Covid-19?

\subsubsection{The quantitative part}

In the quantitative part, the statistical population of this study included all women working in educational settings in Tehran and the age range of the respondents was 29 to 61 years. Of this statistical population, 404 people were selected according to the available sampling method based on Kline's theory (2015) to select 200 to 500 samples in using structural equations. The inclusion criteria were as follows: 1. Female 2. Married 3. Working in educational settings 4. Interest in participation. Before the study, necessary explanations about responding and purpose of the study 
were provided and by emphasizing the privacy of information, they were asked to answer the questions honestly. After completing the questionnaires, data were analyzed by Amos 23 and SPSS 18 using descriptive statistics (center-orientation indices and dispersion indices) and inferential statistics (one-sample t-test, Friedman test).

\subsection{Measurement}

In this study, interview was used for data collection in the qualitative part and in the quantitative part, a researcher-made questionnaire was used. In the current study, to estimate reliability of interview coding, test-retest method was used. Here, for the criterion of acceptability to improve scientific accuracy, validity, and reliability, the points made by Morse et al. (2002) are used that are sensitivity of the researcher in methodological coherence, sample appropriateness, finding repeatability, and use of feedback. Research quality is highly dependent on the skill and sensitivity of the researcher. Creativity, skill, sensitivity, and flexibility ensure reliability and validity. For example, in this study, data were analyzed constantly that led to questions that lengthened sampling to reach the required limit. For this reason, sampling continued until all results were repeated. Lack of sensitivity of the researcher during all research stages threatened its validity that its results will emerge in the final assessment criteria. Also, the findings were sent to experts to receive their opinions and comments. For validity, the results of analysis and coding were given to 7 people (including 4 participants) and 3 people outside the study and their views on the extracted codes, conceptual labels, and data content were received.

After obtaining the components through interviews, the researchers converted them into a questionnaire that its face validity and content validity were confirmed by 7 professors of this field of study. In Table 3, reliability of the questionnaire is examined using Cronbach's alpha and in Fig. 1 and Table 2, construct validity using factor analysis is investigated. The researcher-made questionnaire includes 29 questions that its details with reliability values of variables are presented in Table 3.

Table 3 Reliability examination using Cronbach's alpha

\begin{tabular}{lllll}
\hline Main theme & Subtheme & $\begin{array}{l}\text { Number of } \\
\text { items }\end{array}$ & Numbers & $\begin{array}{c}\text { Cron- } \\
\text { bach's } \\
\text { alpha }\end{array}$ \\
\hline Advantages & Economical 6 & 4 & $1-4$ & .70 \\
& Psychological 2 & 5 & $5-9$ & .70 \\
& Health 3 & 7 & $10-16$ & .86 \\
& Family cohesion 1 & 5 & $17-21$ & .85 \\
& Organizational 5 & 5 & $22-26$ & .80 \\
& Educational 4 & 4 & $27-30$ & .70 \\
& Lack of separation between work & 3 & $31-33$ & .72 \\
Disadvantages & and personal issues 1 & & & .71 \\
& Lack of face-to-face position 2 & 3 & $34-36$ & .71 \\
\hline
\end{tabular}




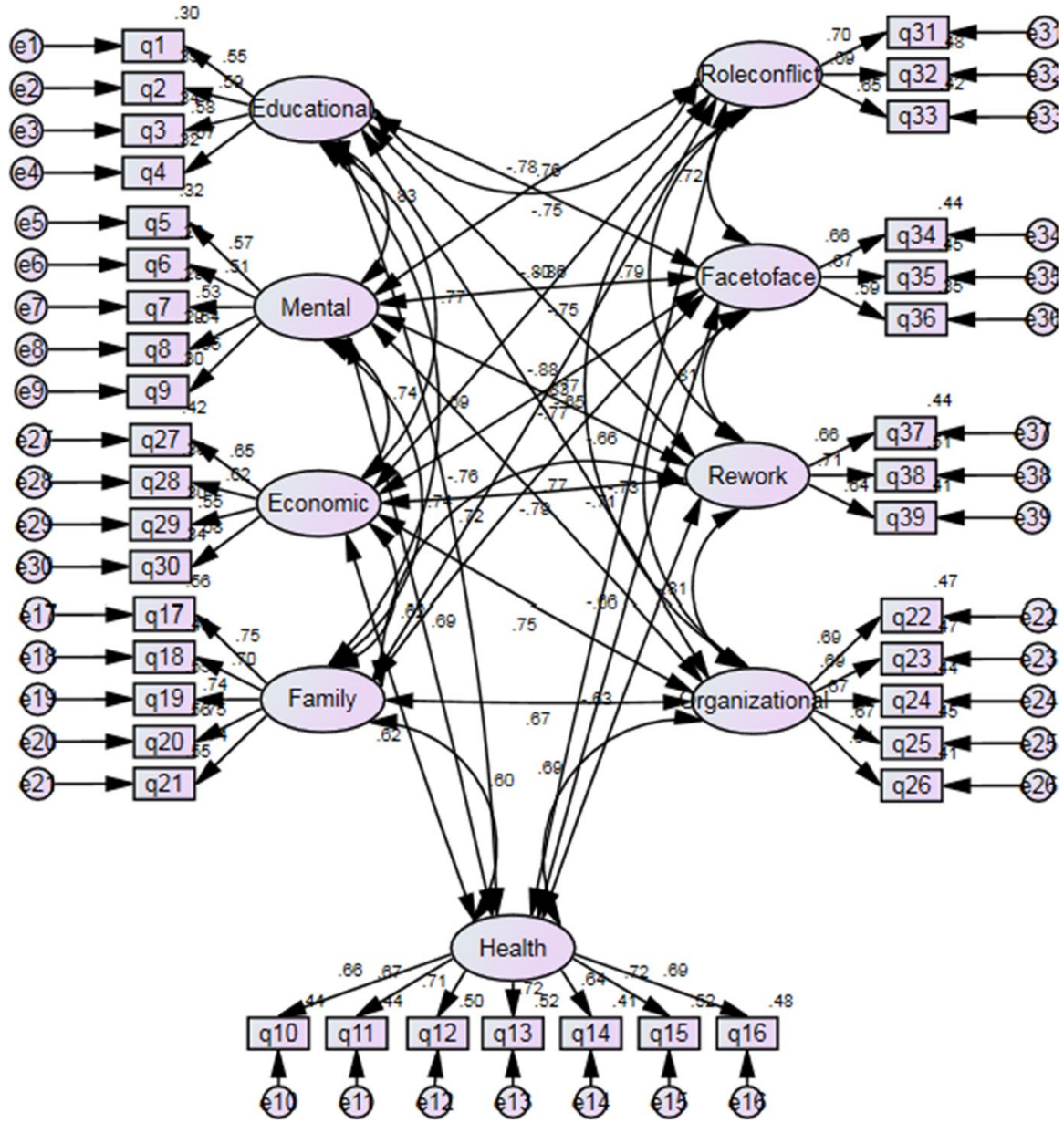

Fig. 1 Confirmatory factor analysis of the questionnaire

In the following, definitions of the words in Table 3 are given.

Family cohesion refers to emotional bonds between family members (Azizi et al., 2018). Mental security is a kind of internal peace that allows people concentrate on solutions for different problems (Dehghani \& Ebrahimi, 2019). Health provides complete physical and mental and social welfare for people (Yazdi et al., 2018). Economy is how rare sources are used to produce valuable goods and services and their distribution among people (Salvatore, 2003). Education means learning and teaching (Vasiq \& Gharamaleki, 2016). Organization is a social phenomenon that is deliberately coordinated with well-defined boundaries and works to meet goals based on a permanent hierarchy (Robbins, 1990).

Work and family conflict is a form of internal role conflict in which career roles and family roles are incompatible in some ways (Greenhaus \& Beutell., 1985). Face-to-face education means being in an educational situation directly and without 
intermediaries (Sadeghi et al., 2017). Reworking means unnecessary efforts to redo a process or activity that was done wrong for the first time (Love, 2002). To examine construct validity, confirmatory factor analysis was used and its results are presented. In Table 4, goodness of fit indices are presented.

As can be seen in Table 4, all values are close to goodness of fit indices and indicate desirability of the structural pattern. RMSEA index is smaller than 0.08; as a result, the research model has acceptable goodness of fit and is confirmed. Adaptive fit indices including CFI, GFI, IAGFI, TLI, and IFI all indicate model desirability and acceptability and show values larger than 0.90. RMSEA index that represents the destination fit shows 0.19 that represents acceptable goodness of fit. In sum, the collected data are acceptable and the developed model is confirmed. In Fig. 1, the confirmatory factor analysis diagram with factor loadings for each question is presented.

\section{Findings}

In Table 5, the main theme, subtheme, and the first floor of the qualitative part are presented. Also, by using the quantitative part, the items are classified.

In Table 6, the descriptive characteristics of research variables including center orientation and dispersion indices are presented.

In order to compare the average opinions of the respondents with the default average 4, one-sample t-test was used (Table 8). First of all (Table 7), average descriptive characteristics of variables and the results of one-sample t-test are presented.

In Table 8, the results of one-sample t-test are presented.

Respondents stated that one of the advantages of teleworking is family that has the highest rank in this study. One of the components of family is taking care of children. Respondents stated that when they go to their workplace, they face many problems related to taking care of their children that forces them to employ a babysitter and pay almost half of their income. Those who had young and teenage children stated that they have more problems in taking care of their children, because younger children are more dependent on their mother and being away from them is very difficult and problematic. For this reason, during teleworking, mothers spend more time at home and can have more time to take care of their children and there is no need to par for babysitter employment. Moreover, they stated that due to fatigue and lack of sufficient time, in many occasions, they give fast foods to their children and this damages their eating habits, but this problem is solved during teleworking to a large extent.

Table 4 Goodness of fit indices of the research model

\begin{tabular}{llllllllll}
\hline Goodness of fit indices & $\chi^{2}$ & $d f$ & $\begin{array}{l}\chi^{2} \\
d f\end{array}$ & AGFI & IFI & TLI & CFI & GFI & RMSEA \\
\hline Research model & 764.62 & 666 & 1.14 & .90 & .98 & .98 & .98 & .91 & .019 \\
\hline
\end{tabular}




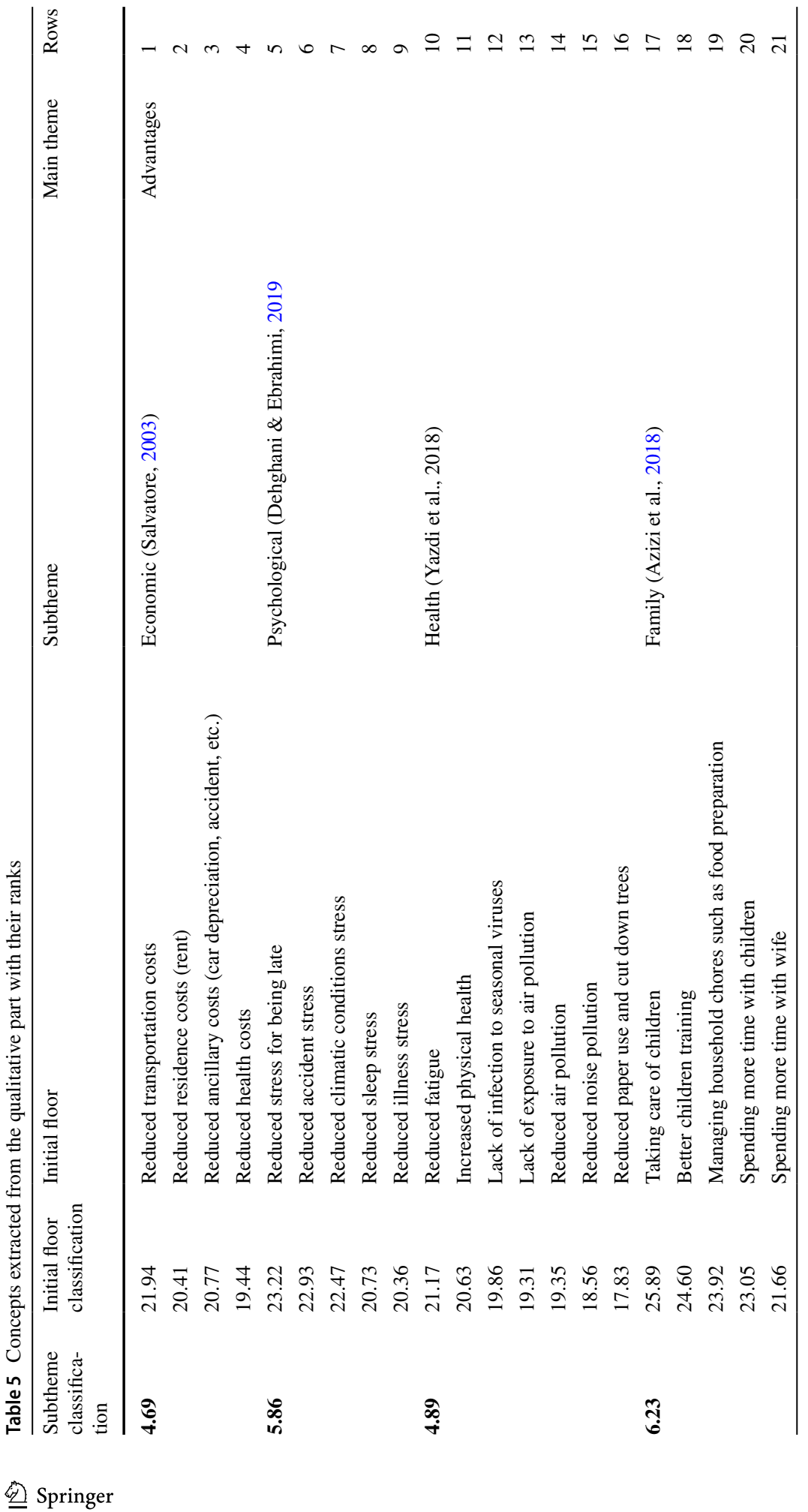




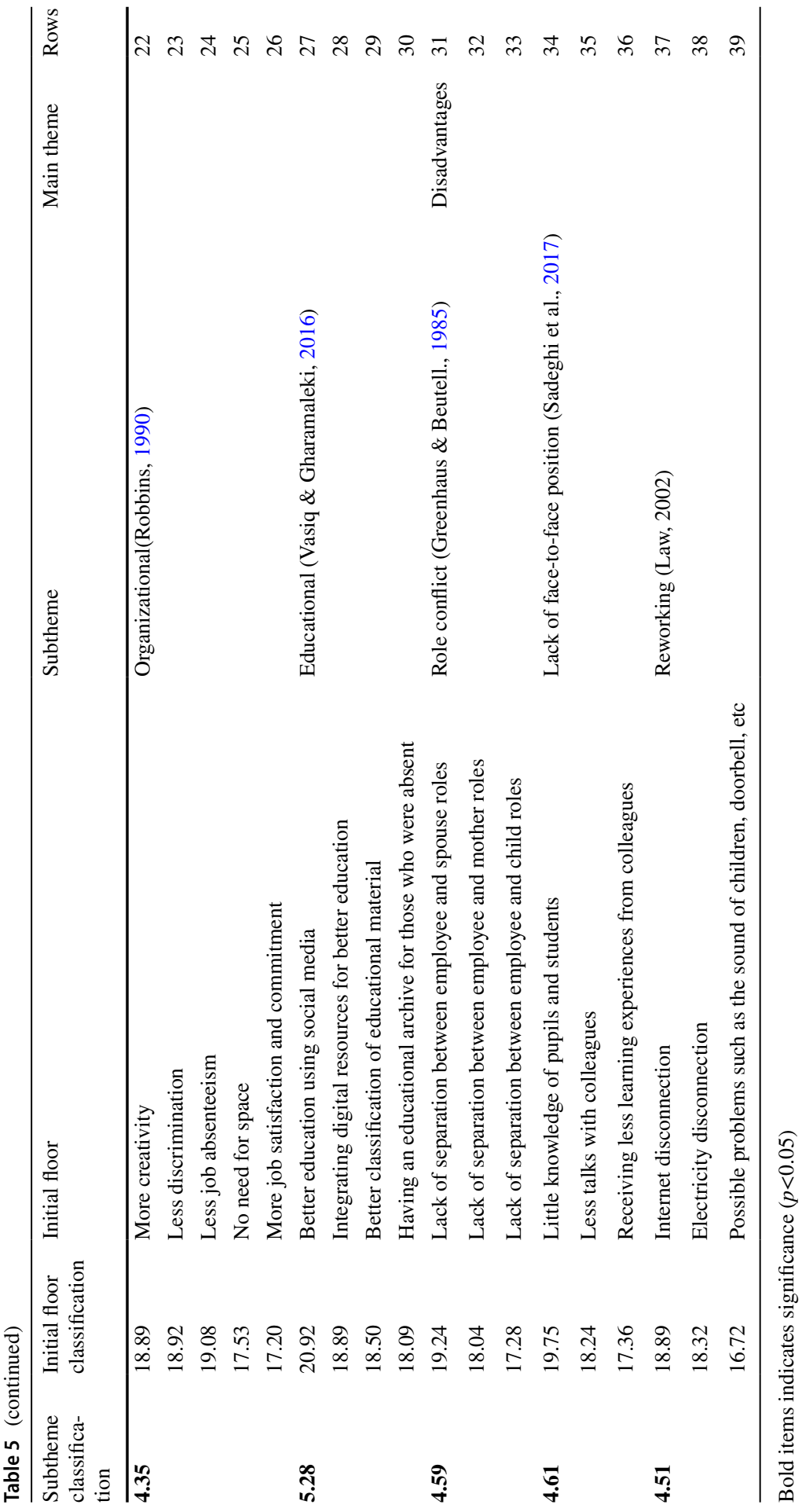


Table 6 Descriptive characteristics of research variables

\begin{tabular}{lcccccc}
\hline Variable & Mean & Median & Std. Deviation & Variance & Minimum & Maximum \\
\hline Family & 25.27 & 25 & 8.00 & 64.08 & 11.00 & 40.00 \\
Mental & 23.94 & 24 & 6.05 & 36.66 & 13.00 & 35.00 \\
Health & 30.41 & 30 & 10.47 & 109.71 & 10.00 & 49.00 \\
Economic & 17.13 & 17 & 5.67 & 32.24 & 4.00 & 28.00 \\
Organizational & 20.81 & 21 & 7.44 & 55.44 & 7.00 & 35.00 \\
Educational & 18.17 & 18 & 5.33 & 28.42 & 4.00 & 28.00 \\
Role conflict & 11.95 & 12 & 4.92 & 24.27 & 3.00 & 21.00 \\
Face to face & 12.09 & 12 & 4.84 & 23.51 & 3.00 & 21.00 \\
Rework & 11.86 & 12 & 4.86 & 23.62 & 3.00 & 21.00 \\
\hline
\end{tabular}

Table 7 Average descriptive characteristics of research variables

\begin{tabular}{llll}
\hline Variable & $\mathrm{N}$ & Mean & Std. Deviation \\
\hline Family & 404 & 5.05 & 1.60 \\
Mental & 404 & 4.78 & 1.21 \\
Health & 404 & 4.34 & 1.49 \\
Economic & 404 & 4.28 & 1.41 \\
Organizational & 404 & 4.16 & 1.48 \\
Educational & 404 & 4.54 & 1.33 \\
Role conflict & 404 & 3.98 & 1.64 \\
Face to face & 404 & 4.03 & 1.61 \\
Rework & 404 & 3.95 & 1.62 \\
\hline
\end{tabular}

Another advantage of teleworking was its mental importance. Respondents stated that they experience a lot of stress to get prepared and go to their workplace. This stress was higher for mothers who had to spend longer distance because factors such as long distance, traffic, accidents, waking up late, and

Table 8 One-sample t-test

\begin{tabular}{lllll}
\hline Variable & $\mathrm{t}$ & $\mathrm{df}$ & Sig. (2-tailed) & Mean Difference \\
\hline Family & 13.25 & 403 & .00 & 1.05 \\
Mental & 13.08 & 403 & .00 & .78 \\
Health & 4.63 & 403 & .00 & .34 \\
Economic & 4.01 & 403 & .00 & .28 \\
Organizational & 2.19 & 403 & .02 & .16 \\
Educational & 8.18 & 403 & .00 & .54 \\
Role conflict & -.19 & 403 & .84 & -.01 \\
Face to face & .39 & 403 & .69 & .03 \\
Rework & -.56 & 403 & .57 & -.04 \\
\hline
\end{tabular}


irregularity were stressful. During the Corona crisis, women were more stressed like most people, because they had to take care of themselves against the virus and due to using public transport system, this concern was more severe, but during teleworking, these mental problems were solved to a large extent and their stress levels were decreased.

Another advantage of teleworking was its educational importance. Respondents stated that at the workplace, they do not have access to many technologies that have a great impact on education, but during teleworking and by using computer, mobile, and internet, they can improve their education and since students have access to mobiles, they can take advantage of technology. Moreover, they can create video clips and enhance their knowledge about their students and can store this information to send to students who were not present in the class.

Another advantage of teleworking was increased health level. Respondents stated that in school or university, they were experiencing illnesses such as cold or unknown viruses that during teleworking, these problems were solved to a large extent. They added that due to decreased daily traffic, air pollution and noise pollution reduced considerably. Furthermore, during teleworking, due to using digital space in education, paper consumption and tree felling are reduced.

Another advantage of teleworking was promoted economic level. Respondents stated that during teleworking, a lot of their expenses are reduced such as transportation costs, rental costs, babysitting costs, and health improvement costs.

Another advantage of teleworking was organizational importance. During teleworking, teachers and lecturers use more creativity to create video clips and PowerPoints compared to face-to-face sessions. Moreover, they stated that during teleworking, less conflict is observed among employee and due to temporal flexibility, they are rarely absent. They added that due to solving problems related to family, they show more satisfaction and commitment relative to their organization.

Teleworking suffers from disadvantages such as lack of face-to-face situations. They stated that in face-to-face situations, they knew more about students and sometimes, they were aware of their feelings. They stated that in face-to-face situations, they can increase or decrease their daily stress depending on the body language of their students and can take advantage of daily experiences of their colleagues to improve their teaching that during teleworking, these conditions are not available.

Another disadvantage of teleworking is role conflict. Respondents stated that when they are working at home, due to temporal flexibility, expectations from wife, children, and families are more. For example, children may expect to play with them while teaching.

Another disadvantage of teleworking is reworking. They stated that due to different reasons such as electricity or internet shutdown, they had to hold sessions again.

Table 8 shows that family, psychological, health, economical, organizational, and educational variables are significant at the error level of $0^{<} 0.05$ and family-work conflict, face-to-face position, and reworking variables are not significant. According to the descriptive characteristics in Table 7, it can be said that the sample group in advantage variables (family, psychological, health, economical, organizational, and educational) shows a positive view relative to disadvantage variables (family-work 
conflict, lack of face-to-face position, and reworking). In Fig. 2, average research variables are presented.

\section{Discussion and Conclusion}

Information technology and communications have influenced different aspects of the society and careers. One of these influences is integration of the mentioned divisions according to time and place of working activities using information and communication infrastructures. This study aimed to investigate the consequences of teleworking through the Internet among married women working in educational settings. For this purpose, qualitative and quantitative methods were used. In answering the first question about the advantages of teleworking for working women in educational setting, in the qualitative section and through interviews with scholars, teachers, and university lecturers, it was found that teleworking through the Internet has educational, psychological, economic, health, family, and organizational advantages. Data analysis showed that family, psychological, educational, health, economic, and organizational variables are the most important ones for married women. Moreover, the results of the quantitative part showed that in the variable of family, items including taking care of children, better training, managing household affairs, spending more time with children, and spending more time with husband are the most important ones. Since the researchers in the qualitative part obtained 6 advantages for teleworking through the internet in the interview, these 6 factors are compared with other studies.

In answering the first question about the disadvantages of teleworking for married working women in educational setting, the results showed that teleworking has disadvantages such as role conflict, lack of face-to-face position, and reworking. In

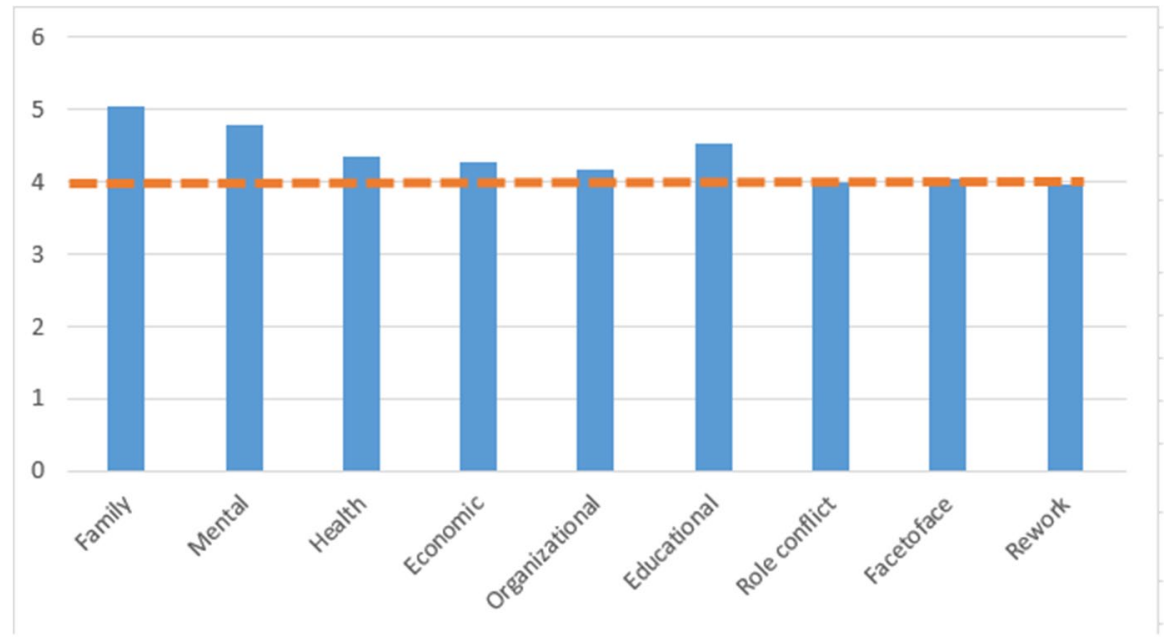

Fig. 2 Average research variables 
explaining these results, it can be said that in developing countries or countries that experience teleworking for the first time, these disadvantages are common. Due to lack of infrastructures and since teleworking conditions have just emerged, teleworkers may face problems such as role conflict and if the teleworking process continues and people become familiar with it through mass media, the disadvantages may disappear.

About the second research question, the findings showed that family, mental, educational, health, economic, lack of exposure to face-to-face situations, role conflict, reworking, and organization variables have the largest mean values, respectively.

The results of this study are consistent with Belzunegui-Eraso \& Erro-Garcés (2020) who emphasized the role of teleworking in increasing work safety and health during Covid-19 pandemic; Chung and Van der Horst (2018) who investigated the effects of teleworking on working women in England and concluded that teleworking can increase staying at work; (Pordelan et al., 2021; Pordelan \& Hosseinian, 2021) who stated that digital sources can be efficient in educational processes and Nguyen (2021) who pointed out that teleworking leads to reduced costs and Andalib and Rostami (2016) who concluded that teleworking through reduced burnout leads to better organizational performance.

One reason that can lead to motivation for working women to select this method is creating balance between life and work. For married women, teleworking is the only way to take care of children and work simultaneously (since due to Covid19 pandemic, it is not possible to employ babysitter). This view is consistent with Shojanoori et al. (2015) who investigated the effects of teleworking of married and working women on work-life balance based on communication technology and concluded that the use of technology in teleworking leads to suitable and flexible working hours, increased efficiency of career activities, more stable and motivated workforce, and increased attention to family. In this study, women stated that they were recording some of their educational files during their free time to play them during the class. Flexibility in recording and editing educational files and playing them through online and offline routes leads to more flexible teleworking for working women.

The results of this study support Damghanian and Roozban (2012) who stated that some computer-based careers lead to more flexibility during work and cause positive consequences for working women. Flexibility in educational settings based on technology gives more time to women to manage their family roles and at the same time, perform their responsibilities very well. For this reason, the use of teleworking for women through technology can be useful.

They believe that teleworking is a valuable organizational response to help employees have better family relationships. Creating balance, positive balance, and synergy are three main dimensions of personal life (personal, occupational, family). Balance in work and life, defining the position of the self, career, and family lead to balance among career responsibilities and personal and family commitments and prevent physical, psychological, and spiritual fatigue. For this reason, it can be said that teleworking creates a balance between work and life and family cohesion and psychological peace as well. In this study, classification of variables showed that family and psychological variables are the most important variables, respectively. 
Mental and spiritual characteristics of women are different from men. Therefore, challenges that emerge in the working space can cause mental and spiritual depressions and these aspects have negative consequences for marital relations and can damage intimacy. As a result, compliance among couples changes to dissatisfaction and may lead to separation. In this study, the results showed that one of the advantages of teleworking is improved health that includes reduced fatigue, improved physical health, no exposure to pollutants, reduced noise pollution, reduced air pollution, and reduced use of paper and cut down trees.

Modern technologies such as Internet and virtual space make it possible to have professional works with nonconventional methods. This has led to significant evolution of the market. Teleworkers are rarely exposed to stress compared to other employees. Also, these people show more interest in work. Indeed, this method allows people to be free from crowd and traffic. Moreover, working outside the work space leads to improved nutrition of the employees and they have more opportunities for workouts. Healthier and happier workers show more efficiency and have more commitment. Employers who employ part-time or full-time workers, save furniture costs, necessary equipment for work, rent, and other requirements needed for office. Accordingly, women who select this method can have time to manage their family and household affairs and at the same time, carry out their career responsibilities very well. In this regard, in many countries, women are the major users of this working method.

The quantitative findings of this study are consistent with Mugruza-Vassallo and Suárez (2016) who stated that a relationship exists between the use of technology and communication efficiency, Giovanis (2018a, b) who pointed out that a significant relationship exists between teleworking and happiness among women, Karácsony (2021) who pointed to a positive relationship between teleworking and job satisfaction during the Covid-19 crisis, Busu and Gyorgy (2021) who showed that a positive relationship exists between teleworking and job performance, and Giovanis (2018a, b) who stated that a direct relationship exists between teleworking and reduced traffic and pollution.

The findings of this study were not consistent with De Vries et al. (2019). They concluded that teleworking does not lead to increased organizational commitment while in the current study, the participants in both quantitative and qualitative parts claimed that teleworking for the organization can be effective because it increases job satisfaction and commitment of employees. One reason that can explain this issue is that teleworking conditions before and after the Covid-19 pandemic are different.

The results of this part of study in two parts of reworking and lack of face-toface interaction are consistent with Fathian and Jahani (2020 who pointed out that internet infrastructure problems and inability to pass intra-organizational courses are among the concerns of teleworkers. The results of this study in work and family conflict section are not consistent with Madsen (2003) and Fílardí et al. (2020) who stated that teleworkers face less work and family conflicts. One reason that can explain this issue is that this study was conducted during Covid-19 pandemic and people spent all of their time in the house and they rarely went out even for fun while in previous studies, people were not have to stay at home and quarantine themselves. The results of this study regarding conflict between career and family are consistent 
with Delanoeije et al. (2019) who stated that teleworking causes conflicts between house and career and a study by Zhang et al. (2020) who pointed out that families with children suffer from more conflicts between career and family affairs.

\subsection{Conclusion}

This study aimed to investigate the effects of teleworking through the Internet on married women who work in educational settings. The findings showed that teleworking may have positive consequences especially for family and psychological aspects. According to the results, it can be said that provision of teleworking conditions for married women can lead to family cohesion and promote their psychological security and reduce costs and increase job satisfaction and commitment at the organizational level. Finally, it should be said that information technology has created higher flexibility and motivation for organizations and their employees through teleworking. However, safety and health factors have to be investigated in future studies.

\subsection{Limitations}

One of the limitations of this study is the time domain, because the study is conducted when many people had to have teleworking conditions due to the fear of the Covid-19 epidemic. For this reason, it is suggested to conduct similar studies when the pandemic is over and compare the results before and after the pandemic.

\subsection{Future works}

The future researchers are recommended to investigate successful factors in using teleworking through the Internet to indicate which factors lead to the use of the Internet as a teleworking instrument. Also, by using casual-comparative studies, job satisfaction and commitment of teleworker and non-teleworker women should be investigated.

Acknowledgements The authors appreciate the experts and the students who participated in this study.

Author contribution NP designed the interventions, held and managed the sessions, analyzed data, and developed the article. SH contributed in data analysis, designed the research method, and contributed in article development. HH contributed in data analysis, designed the research method, and contributed in article development. SKH contributed in data analysis, designed the research method, and contributed in article development. MKH contributed in data analysis, designed the research method, and contributed in article development. All authors read and approved the manuscript.

\section{Declarations}

Conflict of interest The Authors declare that they have no conflict of interest.

Informed consent Informed consent was provided by all the participants. 


\section{References}

Adams-Prassl, A., Boneva, T., Golin, M., \& Rauh, C. (2020). Inequality in the impact of the coronavirus shock: Evidence from real time surveys. Journal of Public Economics, 189, 104245. https://doi.org/ 10.1016/j.jpubeco.2020.104245

Andalib, D., \& Rostami, K. (2016). Impact on teleworking on organizational performance with structural equation modeling. Journal of Business Administration Researches, 8(16), 141-159.

Azizi, L. S., Sepah Mansour, M., \& Kolchak Entezar, R. (2018). Modeling of family adaptability and cohesion in the family of autistic children based on family resources, coping strategies and perceived stress. Contemporary Psychology, Biannual Journal of the Iranian Psychological Association, 12(2), 186-197.

Balali, E., Bakhtiari Safar, Z., Mohammadi, A., \& Mohagegi, H. (2017). Effective factors of role conflict in women and its effect on family conflicts in Hamadan. Journal of Applied Sociology, 27(4), 117-132.

Baqaee, D., Farhi, E., Mina, M., \& Stock, J. H. (2020). Reopening Sce- narios. Tech. rep. National Bureau of Economic Research. https://www.brookings.edu/wp-content/uploads/2020/06/Baqaee-etal-conference-draft.pdf

Beck, U., \& Wynne, B. (1992). Risk SOCIETY: Towards a new modernity. Sage.

Belzunegui-Eraso, A., \& Erro-Garcés, A. (2020). Teleworking in the context of the Covid-19 crisis. Sustainability, 12(9), 3662. https://doi.org/10.3390/su12093662

Bick, A., Blandin, A., \& Mertens, K. (2020). Work from Home after the Covid-19 Outbreak. CEPR Discussion Paper No. DP15000, Available at SSRN: https://ssrn.com/abstract=3650114

Boca, D. D., Oggero, N., Profeta, P., \& Rossi, M. (2020). Women's work, housework and childcare, before and during COVID-19.| CESifo Working. 8403, Available at SSRN: https://ssrn.com/abstr act $=3644817$

Busu, M., \& Gyorgy, A. (2021). The Mediating Role of the Ability to Adapt to Teleworking to Increase the Organizational Performance. The AMFITEATRU ECONOMIC Journal, 23(58), 654-654.

Chung, H., \& Van der Horst, M. (2018). Women's employment patterns after childbirth and the perceived access to and use of flexitime and teleworking. Human Relations, 71(1), 47-72. https://doi.org/10. $1177 / 0018726717713828$

Damghanian, H., \& Roozban, F. (2012). Teleworking consequences on the women employees.

Darouei, M., \& Pluut, H. (2021). Work from home today for a better tomorrow! How working from home influences work-family conflict and employees' start of the next workday. Stress and Health. https:// doi.org/10.1002/smi.3053

De Vries, H., Tummers, L., \& Bekkers, V. (2019). The benefits of teleworking in the public sector: Reality or rhetoric? Review of Public Personnel Administration, 39(4), 570-593. https://doi.org/10.1177/ $0734371 X 18760124$

Dehghani, H., \& Ebrahimi, H. (2019). Studying the feeling of social and psychological security with a tendency toward superstition (case study: Isfahan University students). Strategic Rssearch on Social Problems in Iran University of Isfahan, 8(4), 99-122.

Delanoeije, J., Verbruggen, M., \& Germeys, L. (2019). Boundary role transitions: A day-to-day approach to explain the effects of home-based telework on work-to-home conflict and home-to-work conflict. Human Relations, 72(12), 1843-1868. https://doi.org/10.1177/0018726718823071

Fathian, M., \& Jahani, A. (2020). Evaluating effective obstacles in implementation of teleworking. Commercial Strategies, 9(50), 17-30.

Fílardí, F., de Castro, R. M., \& Zaníní, M. T. F. (2020). Advantages and disadvantages of teleworking in Brazilian public administration: Analysis of SERPRO and Federal Revenue experiences. Cadernos EBAPE. BR, 18(1), 28-46.

Gálvez, A., Tirado, F., \& Alcaraz, J. M. (2020). “Oh! Teleworking!” Regimes of engagement and the lived experience of female Spanish teleworkers. Business Ethics: A European Review, 29(1), 180192. https://doi.org/10.1111/beer. 12240

Ghafourifard, M. (2020). The promotion of virtual education in Iran: The potential which turned into reality by Coronavirus. Iranian Journal of Medical Education, 20, 33-34.

Giovanis, E. (2018a). Are women happier when their spouse is teleworker? Journal of Happiness Studies, 19(3), 719-754.

Giovanis, E. (2018b). The relationship between teleworking, traffic and air pollution. Atmospheric Pollution Research, 9(1), 1-14. 
Gold, M., \& Mustafa, M. (2013). Work always wins: Client colonisation, time management and the anxieties of connected freelancers. New Technology, Work and Employment, 28(3), 197-211. https://doi. org/10.1111/ntwe.12017

Greenhaus, J. H., \& Beutell, N. J. (1985). Sources of conflict between work and family roles. Academy of Management Review, 10(1), 76-88.

Gregory, A., \& Milner, S. (2009). Editorial: Work-life balance: A matter of choice? Gender, Work and Organization, 16(1), 1-13. https://doi.org/10.1111/j.1468-0432.2008.00429.x

Groen, B. A., Van Triest, S. P., Coers, M., \& Wtenweerde, N. (2018). Managing flexible work arrangements: Teleworking and output controls. European Management Journal, 36(6), 727-735. https:// doi.org/10.1016/j.emj.2018.01.007

Hesse-Biber, S. N., \& Leavy, P. (Eds.). (2010). Handbook of emergent methods. Guilford Press.

Hilbrecht, M., Shaw, S. M., Johnson, L. C., \& Andrey, J. (2008). 'I'm home for the kids': Contradictory implications for work-life balance of teleworking mothers. Gender, Work \& Organization, 15(5), 454-476. https://doi.org/10.1111/j.1468-0432.2008.00413.x

Jaakson, K., \& Kallaste, E. (2010). Beyond flexibility: Reallocation of responsibilities in the case of telework. New Technology, Work and Employment, 25(3), 196-209. https://doi.org/10.1111/j.1468005X.2010.00248.x

Jones, C. J., Philippon, T., \& Venkateswaran, V. (2020). Optimal mitigation policies in a pandemic: Social distancing and working from home (No. w26984). National Bureau of Economic Research.] https://doi.org/10.3386/w26984.

Karácsony, P. (2021). Impact of teleworking on job satisfaction among Slovakian employees in the era of COVID-19. Problems and Perspectives in Management, 19(3), 1. https://doi.org/10.21511/ppm. 19(3).2021.01

Kharabaf, S., \& Abdollahi, M. (2012).. Science growth in Iran over the past 35 years. J Res Med Sci. 17(3):1-5. PMCID: PMC3527047 PMID: 23267381.

Khorrami, M., Atashpour, S. H., \& Arefi, M. (2019). Analyzing the path between positive psychological functions among mothers of children cerebral palsy. Journal of North Khorasan University of Medical Sciences, 10(4), 28-39.

Kinsman F. (1987). The Telecommuters. John Wiley \& Sons: New York. http://worldcat.org/isbn/0471917893

Kline, R. B. (2015). Principles and practice of structural equation modeling. Guilford publications.

Kurland, N. B., \& Bailey, D. E. (1999). Telework: The advantages and challenges of working here, there, anywhere, and anytime. Organizational Dynamics, 28(2), 53-68. https://doi.org/10.1016/S00902616(00)80016-9

Leibovici, F., Santacreu, A. M., \& M. Famiglietti (2020). Reopening the U.S. Economy an Industry at a Time. url: https://www.stlouisfed.org/on-the-economy/2020/may/reopening-us-economy-industry-time

Lister, K., \& Harnish, T. (2019). Telework and its effects in the United States. In Telework in the 21st Century. Edward Elgar Publishing.| https://doi.org/10.4337/9781789903751.00009

Love, P. E. (2002). Influence of project type and procurement method on rework costs in building construction projects. Journal of Construction Engineering and Management, 128(1), 18-29.

Madsen, S. R. (2003). The effects of home-based teleworking on work-family conflict. Human Resource Development Quarterly, 14(1), 35-58. https://doi.org/10.1002/hrdq.1049

McIntosh, M. K. (2005). Working women in English society, 1300-1620. Cambridge University Press. Thttps://books.google.com/books?id=90hrZ9NSLyAC\&dq=Working + women \&lr=\&source=gbs_ navlinks_s

Messenger, J. C., \& Gschwind, L. (2016). Three generations of Telework: New ICT s and the (R) evolution from Home Office to Virtual Office. New Technology, Work and Employment, 31(3), 195-208.

Mokhtarian, P. L., \& Salomon, I. (1994). Modeling the choice of telecommuting: Setting the context. Environment and Planning A, 26(5), 749-766. https://doi.org/10.1068/a260749

Moore, J. (2006). Home working and work-life balance: Does it add to quality of life? Revue Européenne De Psychologie Appliquée, 56, 5-13. https://doi.org/10.1016/j.erap.2005.02.013

Morse, J. M., Barrett, M., Mayan, M., Olson, K., \& Spiers, J. (2002). Verification strategies for establishing reliability and validity in qualitative research. International Journal of Qualitative Methods, $1(2), 13-22$.

Mugruza-Vassallo, C. A., \& Suárez, S. M. (2016). Academia and patents at information and communications technology in South-America productivity. 2016 6th International Conference on Information Communication and Management (ICICM), https://doi.org/10.1109/INFOCOMAN.2016.7784209

Nguyen, M. H. (2021). Factors influencing home-based telework in Hanoi (Vietnam) during and after the COVID-19 era. Transportation, 1-32. https://doi.org/10.1007/s11116-021-10169-5 
Nilles, J. M. (1998). Managing telework: Strategies for managing the virtual workforce (Vol. 6). Wiley'] https://pdfs.semanticscholar.org/207f/00a54bbf6521c95850dc2f2626bb879819ea.pdf

Nozari, H., Sadeghi, M. E., \& Monajemzade, S. S. (2020). Identifying the challenges facing the telecommuting plan and providing solutions for its effective implementation - a case study of the ministry of industry, mines and trade. Innovation Management and Operational Strategies, 1(2), 171-186.

Olson, M. H., \& Primps, S. B. (1984). Working at home with computers: Work and non-work issues. Journal of Social Issues, 40, 97-112. https://doi.org/10.1111/j.1540-4560.1984.tb00194.x

Pordelan, N., \& Hosseinian, S. (2021). Online career counseling success: the role of hardiness and psychological capital. International Journal for Educational and Vocational Guidance, 1-19.

Pordelan, N., Hosseinian, S., \& Lashaki, A. B. (2021). Digital storytelling: A tool for life design career intervention. Education and Information Technologies, 26(3), 3445-3457.

Pulido, J. C. R., \& Lo'pez, F.J.M. . (2005). Teleworking in the information sector in Spain. International Journal of Information Management, 25(2005), 229-239. https://doi.org/10.1016/j.ijinfomgt.2005. 02.002

Rafatjah, M., \& Kheirkhah, T. (2012). The Issues and Challenges of Women's Employment in Iran From the View point of Working Managers. (2012). socio-cultural Development Studies, 1(2), 130-156.

Robbins, S. P. (1990). Organization theory: Structures, designs, and applications, 3/e. Pearson Education India.

Sadeghi, A., Pordelan, N., Abedi, M. R., \& Kaedi, M. (2017). Effectiveness of online and face-to-face counseling with the paradigm of guiding on career self-awareness Development. Career and Organizational Counseling, 9(33), 68-88.

Salvatore, D. (2003). Principles of economics: Based on Schaum's Outline of theory and problems of principles of economics. McGraw-Hill.

Shojanoori, F., Khademi, F., \& Sadatsadidpour, S. (2015). Analysis of effects of employed married women teleworking on keeping balance between work and family. Women's Studies Sociological and Psychological, 13(3), 7-42. https://doi.org/10.22051/jwsps.2016.2142

Sládek, P., \& Sigmund, T. (2021, January). Legal Issues of Teleworking. In SHS Web of Conferences (Vol. 90, p. 01020). EDP Sciences.

Souppaya, M., \& Scarfone, K. (2016). Guide to enterprise telework, remote access, and bring your own device (BYOD) security. NIST Special Publication, 800, 46.

Strauss, A., \& Corbin, J. M. (1997). Grounded theory in practice. Sage.

Tan, P. L., \& Lim, J. (2021). Changes in working women's self-reported levels of stress, fatigue, and quality of interpersonal relationships during COVID-19: A comparison of essential and non-essential workers in Singapore. Fatigue, and Quality of Interpersonal Relationships During COVID-19: A Comparison of Essential and Non-Essential Workers in Singapore (January 29, 2021).'

Toffler, A. (1980). The third wave (Vol. 484). Bantam books.

Vandeweyer, J., \& Glorieux, I. (2008). Men taking up career leave: An opportunity for a better work and family life balance? Journal of Social Policy, 37, 271-294. https://doi.org/10.1017/S004727940 7001742

Vargas-Llave, O., Mandl, I., Weber, T., \& Wilkens, M. (2020). Telework and ICT-based mobile work: Flexible working in the digital age. Publications Office of the European Union.

Vasiq, B., \& Gharamaleki, R. G. (2016). The Concept of Education and its impact on the Architecture of Islamic Schools-(A comparative comparison between Seljuk and Safavid Schools). Iran University of Science \& Technology, 4(3), 40-56.

Woods, P. (2006). Successful writing for qualitative researchers (2nd ed.). Routledge.

Yazdi Feyzabadi, V., Seyfaddini, R., Ghandi, M., \& Mehrolhasani, M. H. (2018). The world health organization's definition of health: A short review of critiques and necessity of a shifting paradigm. Iranian Journal of Epidemiology, 13, 155-165.

Zhang, S., Moeckel, R., Moreno, A. T., Shuai, B., \& Gao, J. (2020). A work-life conflict perspective on telework. Transportation Research Part a: Policy and Practice, 141, 51-68.

Publisher's note Springer Nature remains neutral with regard to jurisdictional claims in published maps and institutional affiliations. 


\section{Authors and Affiliations}

\section{Nooshin Pordelan ${ }^{1}$ D $\cdot$ Simin Hosseinian ${ }^{2}$ D $\cdot$ Hamid Heydari $^{3}$. Sadaf Khalijian ${ }^{4}$ (D) Mohammad Khorrami ${ }^{5}$ (D)}

Nooshin Pordelan

pordelan@srbiau.ac.ir

Simin Hosseinian

Hosseinian@alzahra.ac.ir

Sadaf Khalijian

khalijian@um.ac.ir

Mohammad Khorrami

Khorrami@rocketmail.com

1 Department of Education and Counseling, Faculty of Literature, Humanities and Social Sciences, Science and Research Branch, Islamic Azad University, Tehran, Iran

2 Department of Counselling, Faculty of Education and Psychology, Alzahra University, Tehran, Iran

3 Department of Counseling, Faculty of Education and Psychology, University of Isfahan, Isfahan, Iran

4 Faculty of Educational Sciences and Psychology, Department of Educational Administration and Human Resources Development, Ferdowsi University of Mashhad, Mashhad, Iran

5 General Psychology, Islamic Azad University, Tehran Science \& Research Branch (Isfahan), Isfahan, Iran 